\title{
Analysis of factors involved in the social inclusion process of young people fostered in residential care institutions
}

\author{
Josefina Sala Roca $^{a^{*}}$, Mercè Jariot García ${ }^{b}$, Andreu Villaba Biarnés ${ }^{c}$, Montserrat Rodríguez \\ ${ }^{a}$ Departament de Pedagogia Sistemàtica i Social, Universitat Autònoma de Barcelona, Spain \\ ${ }^{\boldsymbol{b}}$ Departament de Pedagogia Aplicada, Universitat Autònoma de Barcelona, Spain \\ ${ }^{c}$ Fundació Pere Tarres, Universitat Ramón Llull, Spain \\ *Corresponding author fina.sala@uab.cat
}

\begin{abstract}
This study aims to analyze how the characteristics of Youth under custody in foster residences and the characteristics of foster residences affect the sociolaboral insertion after coming of age. This information is important for maximizing the possibilities of an autonomous, positive and satisfactory life after coming of age. The directors of 36 finalist residences that care for young people who will come of age in the same center were interviewed. Information about people who left the residences when they came of age over the past 2 to 5 years $(n=143)$ was gathered. Results show that after leaving the center, girls lived more with their partner, became pregnant at an early age, and did not work although they had received more job training than boys and did not seem to have more work instability. The young people who had been in more than one center had more problems with drugs, did not have a job, have less acceptance of social rules, perseverance at work and emotional regulation than the other young people. The subgroups classified as "successful" scored better than other groups in autonomy; education, acceptance of the rules, perseverance at work, emotional regulation, ability to negotiate and be assertive. More "successful" young people came from centers in which the educators have less children.
\end{abstract}

\section{Introduction}

The effects of institutionalisation on children in orphanages started to be studied in the 40-50s with work by Spitz (1945a, 1945b), Goldfarb (1943, 1944, 1945, 1947, 1955) and Bowlby (1953). Most of these studies focused on the cognitive effects of deprivation. They reported serious prejudices in intellectual development. A large number of works - not exempt from critiques and deficits in their designs - warn of the prejudices of institutionalisation for cognitive, physical and socioemotional development. Nevertheless, Maclean (2003) pointed out that the effects of institutionalisation alone do not lead to pathologic conditions; there are other important environmental aspects after residential care, that are also important. As Rutter 
(1972) indicated in his review of the subject, the problem has to be approached to improve resources and attention for protected children.

As Jones \& Lansdverk (2006) observed, most of the literature about residential care is negative and starts from the assumption that any residential programme will be more restrictive, less family oriented, and will have fewer community connections than the non-residential alternatives (Friman, Osgood, Smith, Shanahan, Thompson et al., 1993; Melton, Lyons \& Spaulding, 1998; Bates, English \& Kouidou, 1997; Kahan, 1984; Marinkovic \& Backovic, 2007; and Whittaker, 1979). Despite the lack of rigorously collected empirical data the consensus among professionals and policymakers is that situations in which placement in a residential facility is needed do exist. Nevertheless, residential care continues to be the main measure used to care for unprotected children in many countries. And in fact, comparative studies do not identify better results in the models of protection (Weyts, 2004). Therefore, more research is necessary to improve the conditions and programmes that are successful in caring for unprotected children. Success is understood as socially positive insertion (work, housing, psychological health, interpersonal relations, etc.) after fostering.

Bullock, Little \& Milham (1993) reviewed the studies on residential care. They report that the best quality of attention was observed when residences focused more on the children than on the centre, when centres promoted a good relationship between children and staff; nevertheless, the deficits in socioemotional development, the instability of the staff and the marginal role of the families constituted a permanent problem. In the same vein, Legault, Anawati \& Flynn (2006) found that the psychological adjustment of fostered youths is associated with better-quality relationships with the caregiver, a smaller number of primary caregivers, a greater number of close friendships, greater use of approach coping strategies, less frequent use of avoidant coping strategies and higher self-esteem. The different agents involved in the care of foster children agree that one of the most important processes is the out of care system. Geenen and Powers (Geenen \& Powers, 2007) analysed the experiences of youths in foster care during their transition into adulthood and found some key themes: (a) self-determination; (b) coordination/collaboration (c) importance of relationships; (d) importance of family; (e) normalising the foster care experience; (f) the Independent Living Programme and $(\mathrm{g})$ issues related to disability.

Fernández del Valle, Álvarez \& Fernanz (1999) studied the situation of 188 young people after being fostered in residences in Asturias (Spain). They reported that the mean duration of a stay in a residence was 6.5 years and a fourth of the sample had remained more than 10 years in residences. Less than half of the sample $(40.5 \%)$ was working and only $8 \%$ was studying. The study reports that $19 \%$ have had problems with the law or related to social transgressions; $2.7 \%$ had been or were in prison (in the general population the rate is $0.1 \%$ ); $37 \%$ of the sample had not managed to find an economically acceptable situation and sociolaboural stability: $10 \%$ of the boys and $26.6 \%$ of the girls were in marginal situations (problems with the law, drugs, prostitution, etc.); $26.6 \%$ of the boys and $23.6 \%$ of the girls were depending on the social services to live; and in many cases they did not have housing. These researchers found that more than $60 \%$ of the young people had achieved positive insertion. They also found that the group that had major social conflicts did not correspond with the group that had been in a residence for the most time, and so they stated that the factors responsible for these problems are outside the residence. Artamendi \& Fernández del Valle (1999) concluded that even though the children have a good opinion of the residences in which they live, there are still many deficiencies: there is no individualisation of educational work, the communication mechanisms with the social services are deficient; the maximum time of the stay in the residence as a protective measure is not clearly stated; there are deficiencies in staff's training; many buildings are still too large and the furniture is of a low standard. The mains areas of progress for children staying in residences are education and autonomy in daily life in the residence. However, the areas with least progress are those related to the family (Bravo \& Fernández del Valle, 1999).

Fernández del Valle \& Casas (2002) pointed out that the Spanish social protection system needs after-care programmes to support young people when they reach the age of eighteen and are required to leave residential care. In some autonomous communities, when the youths leave the residence, the government provides them with some money, and/or the possibility of living in a shared flat supervised by social educators for two years. But the difficulties facing young people living autonomously are significant and as McCoy, McMillen, \& Spitznagel (2008) found, most of them returned to their biological homes.

In Catalonia the resource which is most used in the care of protected children in custody is also foster residence. Few families want foster children and even less want them if the child is older than six years of age. Young people under protection remain in foster residence until they reach eighteen years of age. At this 
point they must leave the residence and they are entitled to minimal economic support depending on the number of years spent in residence. Some of them are offered the possibility of living for a maximum of two years in a shared and supervised flat with better financial conditions. But there is not enough assisted accommodation for all of them. In Spain housing costs are increasing. So the situation for youths who have to leave foster residence when they reach eighteen years of age is especially difficult. Most residences have educational programmes oriented to help protected adolescents to find a job and to prepare for independent survival. After leaving the residence young people frequently visit their educators to ask for advice or help, or just to get in contact.

There are different types of foster residences in Catalonia; some of them specialise in early childhood (from 0 to 4 or 6 years old), others are vertical and look after children of a wide age range (from early childhood to adolescence), and others focus on the last period of protection (from 14 or 16 to 18 years old). There are also intensive residences for protected young people with severe mental illnesses and delinquent behaviour. The educators who work in foster residences must have a Bachelor in Social Education and although they work with all the children in the residence, they are only tutor-educator to some of them. Being a tutor-educator to a child means developing a link with the child and being responsible for his/her needs in all aspects (education, health, family, etc.).

This study aims to analyze how the characteristics of Youth under custody in foster residences and the characteristics of foster residences affect the sociolaboral insertion after coming of age. This information is important for maximizing the possibilities of an autonomous, positive and satisfactory life after coming of age.

\section{Methods}

In order to analyse the relationship between sociolaboural inclusion after coming of age and different variables related to the youth under custody and the foster residence, a descriptive and exploratory study using quantitative methodology has been designed.

\subsection{Participants}

Residences in Catalonia (Spain) that care for protected young people in the final periods are the key informants. To evaluate sociolaboural insertion it is necessary that the young people have had time to get used to their new situation. Therefore, directors were asked about young people that had left the foster residence between two and five years ago.

The directors of 36 finalist residences were interviewed. In Catalonia there are 41 finalist residences (residences that care for young people until they come of age). It was not possible to interview 5 residences due to organisational problems in the homes. Information about people who left the residences when they came of age over the past 2 to 5 years was gathered. So the young people the information referred to were now 20 to 23 years old. Young people diagnosed with a mental disorder or young people with delinquent behaviour and who are in intensive centres have not been included in this research. The final sample contained 143 cases.

\subsection{Instrument}

A structured interview was drawn up in order to collect the information. In this interview, centres were asked the following:

A. Foster residence data:

1) Name of the centre and of the person interviewed.

2) Number of educators.

3) Number of foster children in the residence.

4) Number of collaborative families and volunteers in the centre.

5) Atmosphere of the centre: quiet, noisy or with frequent disputes.

6) Frequency of educator changes.

B. Data of the youths who left the foster residence after coming of age:

7) Gender and age of the youths who left the residence after coming of age

8) Age of entry to the foster residence circuit and data of outcome. 
9) Origin of the youths (from family, from another centre, from the street, other).

10) Evaluation of characteristics of the youths: the centres were asked to evaluate the characteristics of the youths on a scale of 0 to 5: autonomy, interpersonal abilities, acceptance of social rules, perseverance at work, emotional regulation, capacity to negotiate, assertiveness, educational learning.

11) The reasons for entering the foster residence: abandonment, family negligence, physical abuse, family violence, sexual abuse, parental delinquency, parents' decision.

C. Preparation received by the youths upon leaving the centre

12) Level of education achieved (primary studies certificate, secondary studies certificate, university level, professional training).

13) Occupational training: if they received occupational training (yes/no).

14) Preparation upon leaving the centre: if there was any preparation.

15) If the centre made some follow up on the people who have left the centre.

D. Current situation of the youths:

16) Where they live: with family, alone, with partner, in a relationship.

17) Problems that they have had: emotional instability, premature parenting, alcoholism, drugs, problems with the law, difficulties finding a job, professional instability, none.

18) If they have a job.

\subsection{Procedure}

The director of the centre or older educators who knew the cases in detail were interviewed. The interviews were sent to finalist foster residences before visiting them so that the required information could be collected. The anonymity of the centres and adolescents was always guaranteed.

\subsection{Data analysis}

The data was analysed using a commercial statistical package (SPSS/PC). Descriptive test, t-test, chisquare test and discriminant analysis were performed.

\section{Results}

\subsection{Sample data}

The sample was made up of $47 \%$ boys and $53 \%$ girls. The age of entry to foster residences was between 2 and 17. Significant differences between boys and girls in the age of internment were not observed. $6.5 \%$ of the young people entered from 2 to 6 years old. $13.6 \%$ entered from 7 and 11 years old. A fourth $(24.4 \%)$ entered in the early teen period (12-14 years) and more than half of the sample (53.9\%) entered in middle adolescence (15-17 years).

When at the finalist residence, $52.9 \%$ of the young people came from another centre, $35.7 \%$ from the biological family, $8.4 \%$ from the foster family (of them $4.2 \%$ were fostered within the extended family and $4.2 \%$ were fostered in non-biological families) and $1.4 \%$ from the street. The reasons for entering foster residences in most cases were multiple. The reasons included family negligence (56\%), abandonment (27.7\%), sexual abuse (12.1\%), parents' decision (9.9\%), physical abuse (9.2\%), family violence $(9.2 \%)$ and parental delinquency $(3.5 \%)$.

Only $5.1 \%$ of the protected adolescents did not receive any education, and they were young people who entered the centre after school age (from 16 years onwards). Nevertheless, only $40.1 \%$ of the young protected people graduated from high school, $7.3 \%$ did technical education, and $0.7 \%$ achieved university studies.

One third of young people (33.6\%) lives with their family (biological or extended) at present; almost another third $(27 \%)$ lives with their partner, and the rest live in shared flats $(14.6 \%)$ or alone $(6.6 \%)$. There is a remarkably high percentage of young people $(14.7 \%)$ of whom their residence is unknown. 


\subsection{Successful sociolabour inclusion}

With the aim of clarifying the variables that affect success in sociolabour inclusion a variable called "success" was created. Indicators of success are to have a job and to not have problems with alcoholism, drugs or with the law. Work should allow the young person to reach a degree of autonomy and responsibility in their survival. Nevertheless, not having work should not be an indicator of failure, but must also be combined with other facts such as alcohol problems, drugs or problems with the law. Two of the problems previously highlighted have not been considered: emotional instability (suffered by a third of the sample) and early parenting. These problems alone do not indicate failure, but as they can be clearly related, their relation with "success" has been analysed.

$46.9 \%$ of the young people that have been protected fulfilled the conditions of "success" (to have work and not to have judicial problems, or problems with drugs or alcohol), only $4.9 \%$ fulfilled the conditions of "failure", and $14 \%$ (20) do not fulfil the conditions of "success". Nevertheless, considering that there is no current information for classifying $34.3 \%$ of young people of the sample, it is possible that the indexes of failure were higher.

Considering the low number of young people in the "failure" group, the data of the young people who fulfilled the condition of "success" were contrasted with the rest.

\subsection{Social inclusion and gender}

There are no differences in "success" according to gender. Nevertheless, the situation of girls when they leave the residence is clearly different from that of boys. One of the central elements in this differential profile is early motherhood: $30.4 \%$ of the girls were young mothers, whereas only $9.4 \%$ of the boys became young fathers. This fact also probably explains other differences such as that a large percentage of girls did not work $(26.9 \%$ vs. $11.4 \%)(\mathrm{F} 96,1=3.6 ; \mathrm{P}<0.05)$ in spite of the fact that girls had more occupational training $(75.7 \%$ vs. $58.6 \%)(\mathrm{F} 128,1=4.26 ; \mathrm{P}<0.05)$ and they do not seem to have more difficulties for finding work, as well as the fact that girls live more with their partners $(41.8 \%$ vs. $14.8 \%)$ (F128,6=18.9; $\mathrm{P}<0.01)$.

\subsection{Age of entering the residence and inclusion}

No relation between the age of entrance and successful sociolabour inclusion was found, nor with the residence, work or problems of emotional instability, premature parenting, alcoholism, drugs or law problems.

\subsection{Reason for protection and inclusion:}

No relation between the reasons for protection and successful sociolabour inclusion were found. Nevertheless, data pointed out that the young people who entered due to the parents' decision had more difficulties in finding a job (41.7\% vs. $18.8 \%$; chi square $\mathrm{F} 1,113=3.4 ; \mathrm{P}=0.08)$, but this difference did not reach statistical significance.

A higher percentage of young people who entered due to family negligence lives with their family at present $(40.8 \%$ vs. $25 \%$; chi square $\mathrm{F} 1,136=11.8 ; \mathrm{P}=0.07)$, but this difference did not reach statistical significance. The data showed that the young people who entered due to family negligence had major emotional instability ( $48.5 \%$ vs. $29.9 \%$; chi square $\mathrm{F} 1,113=4$; $\mathrm{P}<0.05)$. Finally, the young people who were abandoned had less premature parenting $(9.4 \%$ vs. $22 \%$; chi square $114.1=2.4 ; \mathrm{P}=0.09)$ than other young people; but this difference did not reach statistical significance.

\subsection{Inclusion and the young people's origins:}

If we compare the origins of the young people who have achieved successful insertion with those who have not, we find in the successful group a large proportion of young people coming from the biological family $(40.9 \%$ vs. $15.4 \%)$ or the extended family $(7.6 \%$ vs. $0 \%)$ when they entered the 
residence. A large proportion of the "not successful" group came from another centre $(69.2 \%$ vs. $45.5 \%)$ (chi square 92,5=10.94; $\mathrm{P}=0.05$ ) (figure 1).

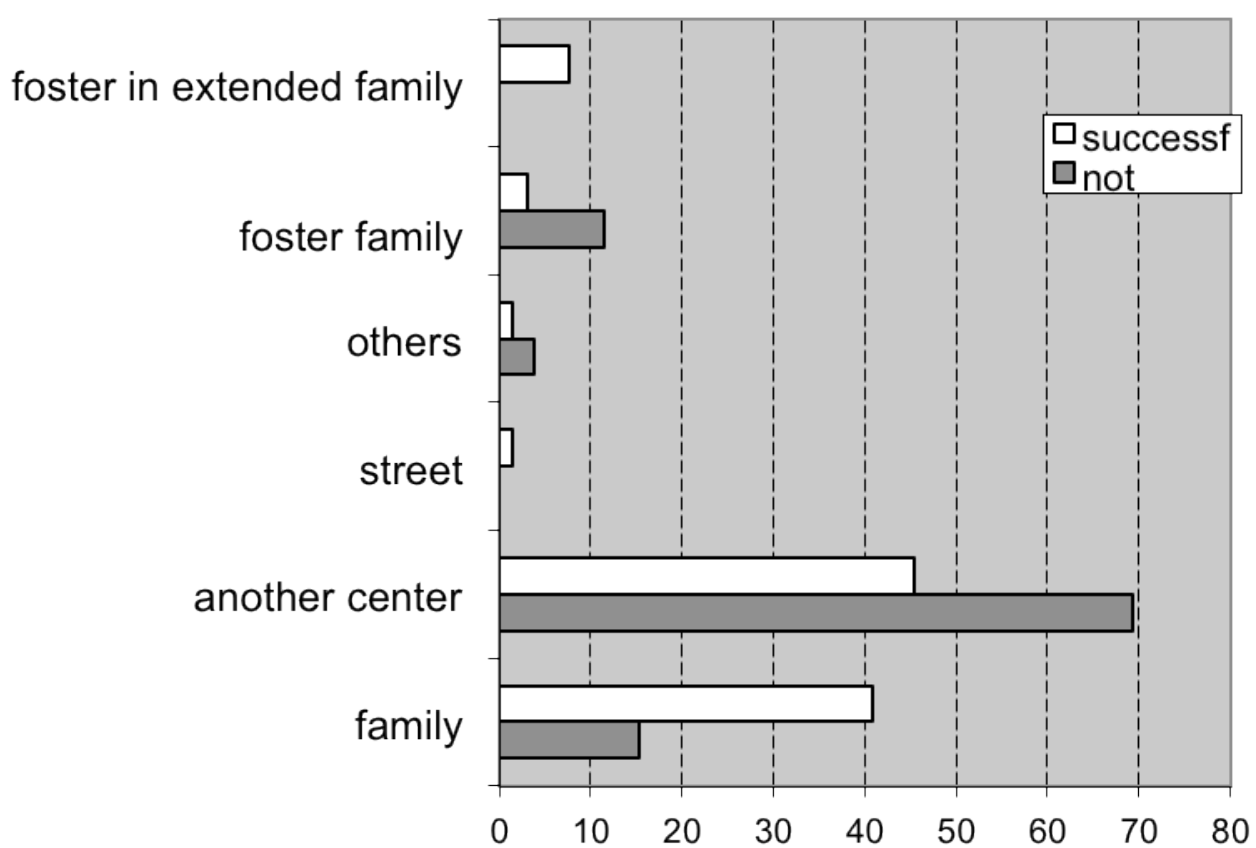

Figure 1. Differences in the sociolaboral inclusion depending on the origin.

A higher proportion of young people who came from another centre had problems with drugs $(23.2$ $\%$ vs. $8.8 \%$; chi square $113,1=4.4, \mathrm{P}<0.05)$ or were without work $(25 \%$ vs. $11.8 \%$; chi square $103,1=3$; $\mathrm{P}=0.07)$ compared to the rest; but the last difference did not reach statistical significance. In addition, these people score lower in acceptance of the social rules $(\mathrm{M}=3.09$ vs. $\mathrm{M}=3.55 ; \mathrm{P}<0.05)$, perseverance at work $(\mathrm{M}=2.73$ vs $\mathrm{M}=3.28 ; \mathrm{P}<0.05)$, emotional regulation $(\mathrm{M}=2.38$ vs $\mathrm{M}=2.78 ; \mathrm{P}<0.05)$ and education $(\mathrm{M}=2.58$ vs. $\mathrm{M}=2,88 ; \mathrm{P}=0.09)$; but the last difference did not reach statistical significance.

\subsection{Relation of characteristics of the young people and the social inclusion:}

The characteristics of the subgroups classified as "successful" and "not successful", differ clearly (figure 2). Specifically, the first group scored higher than the other in autonomy $(\mathrm{M}=3.81 \mathrm{vs.} \mathrm{M}=3.31$; $\mathrm{F} 2,93=4.29 ; \mathrm{P}<0.05)$; education $(\mathrm{M}=2.9$ vs. $\mathrm{M}=2.48 ; \mathrm{F} 2,93=2.95, \mathrm{P}=0.09$ near statistical significance), acceptance of the rules $(\mathrm{M}=2.33 ; \mathrm{F} 2,93=4,8 ; \mathrm{P}<0.05)$, perseverance at work $(\mathrm{M}=3,45$ vs. $\mathrm{M}=2,60$ vs. $\mathrm{M}=1,57 ; \mathrm{F} 2,92=13.18 ; \mathrm{P}<0.001)$, emotional regulation $(\mathrm{M}=2,94$ vs. $\mathrm{M}=2,15 ; \mathrm{F} 2,93=12.46 ; \mathrm{P}<0.01)$, aptitude to negotiate $(\mathrm{M}=3,28$ vs. $\mathrm{M}=2,52 ; \mathrm{F} 2,93=8.69 ; \mathrm{P}<0.01)$ and assertiveness $(\mathrm{M}=3,02$ vs. $\mathrm{M}=2,44$; $\mathrm{F} 2,90=5.12 ; \mathrm{P}<0.05)$. 


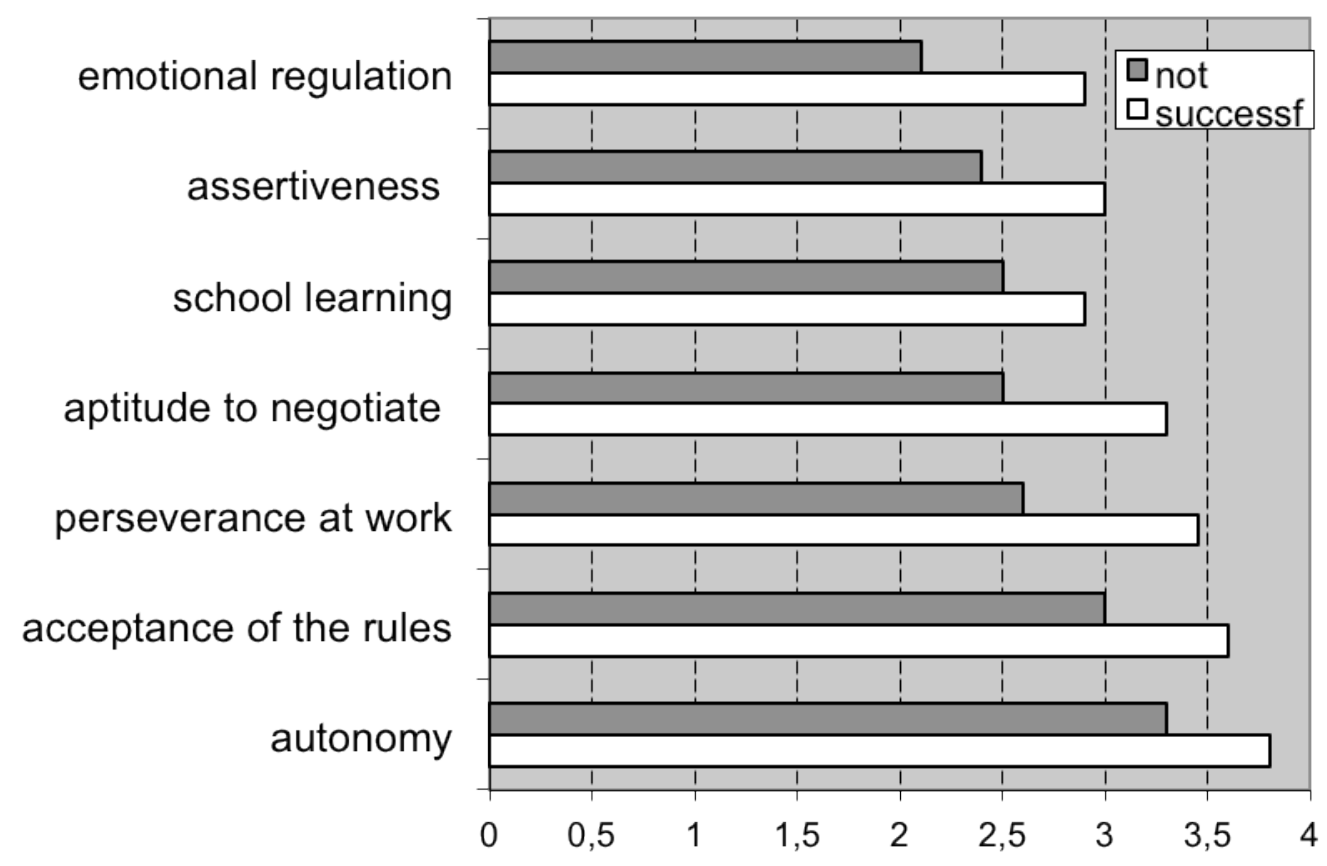

Figure 2. Relation of characteristics of the young people and the social inclusion.

The discriminant analysis showed that the set of characteristics attributed to young people could explain $13.2 \%$ of the variability observed in the variable "success" (Wilks' Lambda $=0.868 ; \mathrm{P}<0.001$ ). Perseverance in work is the characteristic that best summarises the differences between the two groups.

Nevertheless, this profile changes depending on the gender. For boys perseverance at work is the variable that best summarises the differences between the successful and unsuccessful group, and explained $18.1 \%$ of the variability (Wilks' Lambda $=0.818 ; \mathrm{P}<0.01$ ). For girls, the variable that best summarises the differences in the two groups is emotional regulation, which explains $13.2 \%$ of the variability (Wilks' Lambda $=0.868 ; \mathrm{P}<0.05)$.

\subsection{Training and preparation for leaving the residence:}

No relation was found between "success" and school or work training, or the preparation for leaving the residence. These variables were also not related to whether the person works or not, nor the difficulties of finding a job, housing or other problems.

Nevertheless, the characteristics of the young people were related to school training. Young people who had higher levels of training obtained higher scores in assertiveness, $(\mathrm{F} 10,136=2.12 ; \mathrm{P}<0.05)$, acceptance of social rules $(\mathrm{F} 10,136=1.9 ; \mathrm{P}<0.05)$ and perseverance at work $(\mathrm{F} 10,136=1.7 ; \mathrm{P}=0.09)$. In general, the students of university, high school, upper or intermediate professional training received the highest scores.

An important finding is the relation between preparing to leave the residence and socioemotional competences (figure 3). The young people who received preparation for leaving the residence scored higher in: interpersonal relation skills $(\mathrm{M}=3.3$ vs. $\mathrm{M}=2.5 ; \mathrm{P}<0.05)$, acceptance of the rules $(\mathrm{M}=3.4$ vs. $\mathrm{M}=2.6$; $\mathrm{P}<0.05)$, emotional regulation $(\mathrm{M}=2.6$ vs. $\mathrm{M}=1.9 ; \mathrm{P}<0.05)$ and aptitude to negotiate $(\mathrm{M}=3$ vs. $\mathrm{M}=2 ; \mathrm{P}<0.05)$. 


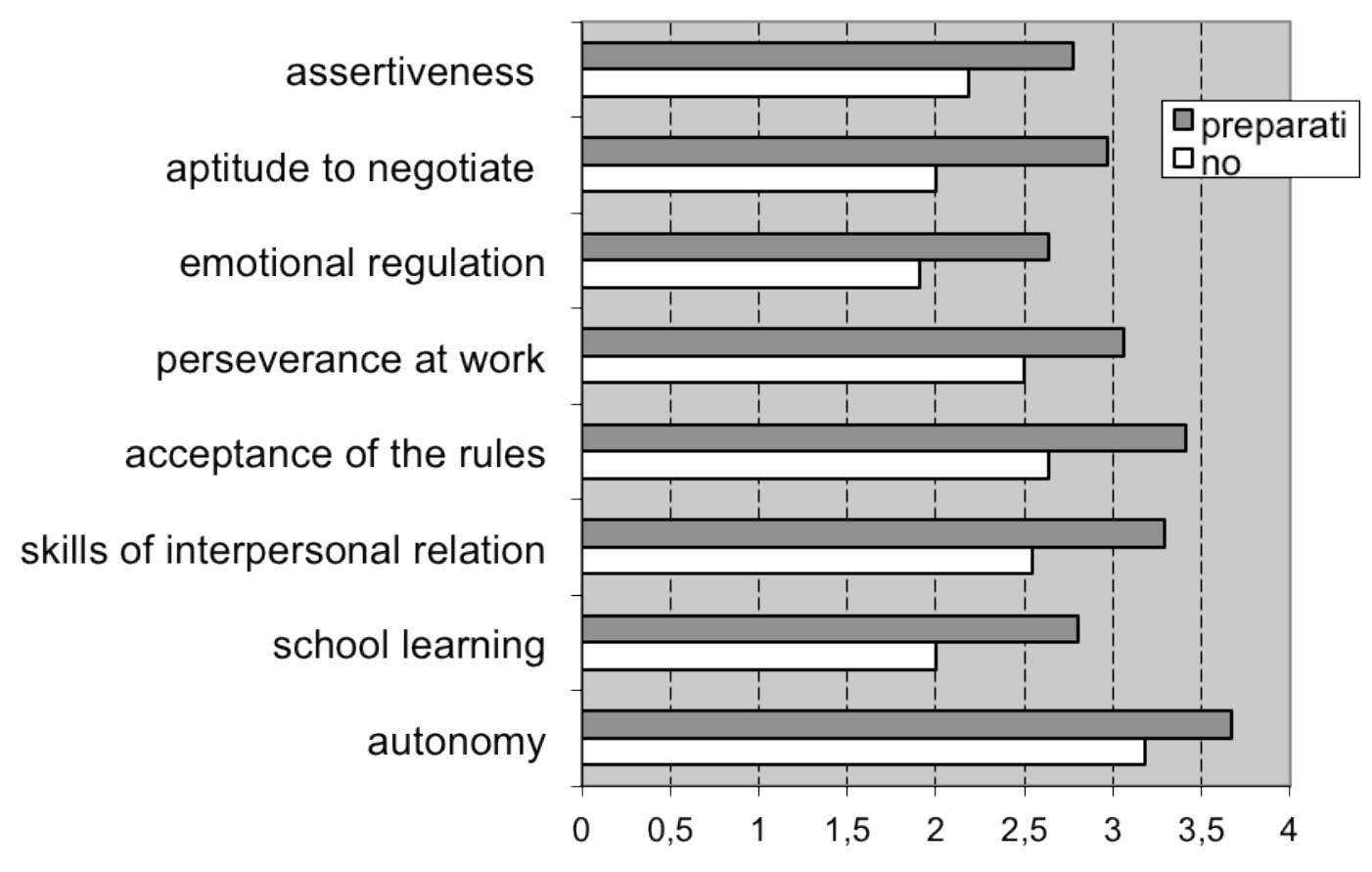

Figure 3. Relation of characteristics and training and preparation for leaving the residence.

\subsection{Characteristics of the centres:}

When the relation between the characteristics of the centres and "success" was analysed it was observed that the young people classified in the subgroup "success" came from centres in which the educators have a lower ratio of children (number of children per educator) $(\mathrm{M}=1.54$ vs. 1.64, F1,63=4.87, $\mathrm{P}<0.05$ ). But there was no relation between the size of the residence and the number of children.

Another element that was related to "success" was the number of collaborative families. The residences with more young people classified in the subgroup "success" had more collaborative families $(\mathrm{M}=10.25$ vs. $\mathrm{M}=8.6, \mathrm{P}=0.08)$, but this difference did not reach statistical significance. There was no relation between "success" and the number of volunteers in the centres.

The atmosphere of the centre was related to judicial problems. In the residences where conflicts are frequent, there were a higher percentage of young people that later had judicial problems $(47.5 \% \mathrm{vs} .28 \%$, chi square $2,208=7.63 ; \mathrm{P}<0.05)$. The young people who came from centres with frequent conflicts also had more difficulties in finding work ( $42.6 \%$ vs. $27.1 \%$; chi square $2,202=4.81 ; \mathrm{P}=0.09$; but this difference did not reach statistical significance).

Following up the young people who left the residence was not related to "success", but curiously it was related to emotional instability. The centres that carried out this follow-up had a higher proportion of young people with these problems than those that did not follow the young people up $(54.3 \% \mathrm{vs} .40 .2 \%)$ (chi square $1,201=3.98 ; \mathrm{P}<0.05$ ); this fact might relate to the fact that with proximity they are more conscious of their problems. The centres that supervise the young people after they leave the residence report less drug problems (9.6 vs. $18.5 \%$, chi square $1,202=3.27 ; \mathrm{P}=0.07$, but this difference did not reach statistical significance).

No relation was found between "success" and how often the educator changes.

\section{Limitations of the study}

Speaking directly with young people who had left residences was very difficult because there is no register with their current location, and it is very difficult to contact them. So the residence directors were used as key informants. However, using key informants introduces a new source of error variance in the study, since they can give imprecise information. 
When they were asked to evaluate some socioemotional competences, different criteria were used since they were different people. This is a new source of error variance.

These sources of error variance increase the noise in the statistic analysis, but do not bias the results. Thus, in spite of this major error variance there are statistically significant results, which show that these statistical relations may actually be more intense.

\section{Discussion}

$46.9 \%$ of the young people that have been protected fulfilled the conditions of "success", only $4.9 \%$ fulfilled the conditions of "failure", $14 \%$ do not fulfil the conditions of "success" and $34.3 \%$ could not be classified in any group because we do not have enough data. Data analysis indicates that the success in socio-labour inclusion was related with the socioemotional abilities, the origins of young people (family/another centre) and lower ratio of children per educator. But sociolabour inclusion was not related with gender, the age of entrance to the residence, reason for protection, school or work training, nor the preparation for leaving the residence, size of residences or how often the educator changes.

The "Success" group scored higher than the other in autonomy, acceptance of the rules, perseverance at work, emotional regulation, aptitude to negotiate and assertiveness. The set of characteristics attributed to young people could explain $13.2 \%$ of the variability observed in the variable "success". This information underlines the need to develop and promote socioemotional competencies. However, the analysis indicates that socioemotional competencies explain a part of this success, but there are other variables involved in this success that must not be neglected. The key socioemotional abilities differ between boys and girls. For boys perseverance seems to be the most important ability and emotional regulation seems to be the most important one for girls. More studies that analyse these differences should assess the need to make specific interventions regarding these differences.

In the "not successful" group more of the youths came from another centre than from their family. In fact young people who came from another centre had more problems with drugs, scored lower in acceptance of social rules, perseverance at work and emotional regulation than those who came from the family. The change of centre can mean breaking the emotional bonds with the educators and an increased sensation of instability. Consequently this could negatively affect the youth's socioemotional development and the capacity to establish social relations and healthy emotional links in adult life. Diverse studies have pointed out that the creation of stable emotional links is necessary to develop social skills and allow positive personal and emotional growth (Eisenberg et al., 1993; Eisenberg et al., 1997; Kliever, 1991; Block \& Block, 1980). In this respect, some researchers pointed out that a stable placement is a good strategy for ensuring more positive outcomes in fostered youths (Jones \& Lansdverk, 2006; Hawkins-Rodgers, 2007). Therefore, the changes of residences during protection and the criteria used to make these decisions must be reconsidered.

These results lead to thinking about the role of the biological family in social insertion when the young person leaves the centre. Data suggest that in spite of the fact that the families neglected the minor and this motivated their protection, the emotional link is maintained and this can help the person when they come of age. Different studies support the preventive intervention in the family (Engels \& Andries, 2007; Fernandez, 2006) and, in fact, a third part of young people returned to their family when they come of age and protection finishes. Therefore, it is necessary to maximise the socioeducative interventions that avoid withdrawing the minor from their family. If it is imperative that the minor maintains family relations during fostering, socioeducative interventions are necessary to prepare the family to develop its present and future function with regard to the minor.

Only $40.1 \%$ of the young protected people graduated from high school, $7.3 \%$ did technical education, and $0.7 \%$ achieved university studies; while these percentages in the general population are: 73.6 $\%, 43.3 \%, 33.4 \%$ (Merino \& García, 2007). So the great inequality upon entering the labour market is evident. Nevertheless it appears that this variable is not related to socio-labour insertion. No relation was found between "success" and school or work training, or the preparation for leaving the residence.

Nevertheless, the characteristics of the young people were related to school training. Young people who had higher levels of training obtained higher scores in assertiveness and acceptance of social rules. In general, the students of university, high school, upper or intermediate professional training received the highest scores. However, these data do not suppose that studies are necessarily responsible for better 
socioemotional competences, but rather it is possible that socioemotional competences influence the educational course of the minor. Both factors probably act together and promote mutually. Furthermore, the young people who received preparation for leaving the residence scored higher in interpersonal relation skills, acceptance of the rules, emotional regulation and aptitude to negotiate. That is, preparation for leaving the residence would not affect sociolabour insertion directly, but it would affect sociolabour insertion indirectly promoting socioemotional competences. This underlines the importance of education carried out by residence staff, and the need to promote this task (Garcia, Rodríguez, Sala \& Villalba, 2008).

The situation of girls is clearly different from that of boys: $30.4 \%$ of the girls were young mothers, whereas only $9.4 \%$ of the boys became young fathers, and there are more unemployed girls than boys in spite of the fact that girls had more occupational training. This profile suggests that many of the protected girls could see the creation of their own family as a way of achieving their emotional and economic stability; without considering that this situation places them in a dependent relationship of which they will be unable to get out if significant problems arise, and that they are at an increased risk of suffering abusive experiences.

Young people who entered due to family negligence had major emotional instability. It might be that this major instability is related to a closer relation with the family during protection; or that the minor was separated from their parents against their will. Different studies show that adolescents who have suffered different types of maltreatment are at an increased risk of substance abuse (Moran, Vuchinicha \& Hallb, 2004, Swanston et al., 2003), increased difficulties establishing stable sentimental relations, an increased risk of suffering abuse from their partner (Romito et al., 2003), and practice more risky sexual activity (Rodgers et al., 2004). In the same vein, Fergusson \& Horwood (1998) found that fostering or adoption does not prevent the appearance of behavioural problems in adolescence. Nevertheless there are no studies that analyse how visits with the biological family during fostering affects children's emotional wellbeing.

The young people classified in the subgroup "success" came from centres in which the educators have a lower ratio of children (number of children per educator); but there was no relation to the size of residences (number of children). These data point out the importance of educational individualisation in agreement with Bullock et al. (1993). A lower ratio means the child has more individual attention, and this greater attention means more possibilities of success. Moreover, the atmosphere of the centre was related to judicial problems. In the residences where conflicts are frequent, there were a higher percentage of young people that later had judicial problems.

\section{Conclusions}

Almost half of the young people underwent positive sociolabour inclusion. But intervention strategies to increase the number of young people who successfully achieve sociolabour insertion are necessary. According to the information in this study some of the strategic lines could be:

1. Individualised attention: low minor-educator ratios and programmes of individualised attention.

2. Permanency of the minor in the same centre during the whole residential fostering if possible.

3. Educational projects that include socioemotional competences such as perseverance, emotional regulation, aptitude to negotiate and assertiveness.

4. Educational programmes that could increase the education level, increasing resources for extra support lessons, improving motivation for studying and reducing the number of young people who leave school.

5. Socioeducational projects that include and involve the biological family and collaborative families in the social and educational attention to the minor.

6. Preparation for leaving the residence and the supervision of the young people by an adult who could be a reference to them in their beginning of autonomous life.

7. Promotion of residence projects for labour insertion and the implications of the available resources in the community in this insertion.

8. Promotion of measures that help young people obtain the economic resources that allow them to live autonomously without needing to come back to the family for economic reasons. 


\section{Acknowledgements}

This study was supported by a grant from the Ministry of Education (SEJ2007-61027/EDUC). We would like to thank the FEDAIA and DGAIA for their interest and collaboration in the study, and the residential centres for their collaboration in the collection of data.

\section{References}

Artamendi, M.R. \& Fernández del Valle, J. (1999). Evaluación del proceso en programas de acogimiento residencial. In M.A. Verdugo \& F. Borja (coords.), Hacia una nueva concepción de la discapacidad. Salamanca: Amarú, 393-404.

Bates, B.C., English, D.J. \& Kouidou, G.S. (1997). Residential treatment and its alternatives: A review of the literature, Child and Youth Care Forum, 26 (1), 7-61.

Block, J.H. \& Block, J. (1980). The role of ego-control and ego-resiliency in the organization of behavior. In W. A. Collins (ed.), Development of cognition, affect, and social relations. Hillsdale: Erlbaum, 39101.

Bowlby (1953). Child care and the growth of love. Baltimore, MD: Penguin Books.

Bravo, A. \& Fernández del Valle, J. (1999). Evaluación de objetivos en programas de acogimiento residencial. In M.A. Verdugo \& F. Borja (coords.), Hacia una nueva concepción de la discapacidad. Salamanca: Amarú, 381-392.

Bullock, R., Little, M. \& Milham, S. (1993). Going home: the return of children separated from their families. London: Dartmouth.

Eisenberg, N., Fabes, R. A., Carlo, G., Speer, A. L., Switzer, G. Carbón, M. \& Troyer, D. (1993). The relations of empathy-related emotions and maternal practices to children's conforting behavior. Journal of Experimental Child Psychology, 55, 131-150.

Eisenberg, N., Guthrie, I.K., Fabes, R.A., Reiser, M., Murphy, B.C., Holgren, R., Maszk, P. \& Losoya, S. (1997). The relations of regulation and emotionality to resiliency and competent social functioning in elementary school children. Child Development, 68, 295-31.

Engels, T.C.E. \& Andries, C. (2007): Developing a framework for a family-focused preventive intervention using the Delphi method. International Journal of Child \& Family Welfare, 10(1-2), 2-13.

Fergusson, D. \& Horwood, L.J. (1998). Adoption and adjustment in adolescent. Adoption \& Fostering, 22(1), 24-30.

Fernandez del Valle, J. \& Casas, F. (2002): Child residencial care in the Spanish social protection system. International Journal of Child \& Family Welfare, 3, 112-128.

Fernández del Valle, J.; Álvarez, E. \& Fernánz, A. (1999). Y después... ¿qué? Estudio y seguimiento de casos que fueron acogidos en residencias de protección de menores en el Principado de Asturias. Oviedo: Servicio de Publicaciones del Principado de Asturias.

Fernández, E. (2006). Supporting families: Tracking interactions between families and professionals in Sydney, Australia. International Journal of Child \& Family Welfare, 9(1), 26-40.

Friman, P.C., Osgood, D.W., Smith, G., Shanahan, D., Thompson, R.W., Larzelere, R. \& Daly, D.L. (1993). A longitudinal evaluation of prevalent negative beliefs about residential placement for troubled adolescents. Journal of Abnormal Child Psychology, 24(3), 299-324.

Garcia, M. Rodríguez, M., Sala, J. \& Villalba, A. (2008). El proceso de desinternamiento de jóvenes extutelados para favorecer una inserción sociolaboral positiva. Análisis de la situación actual en los centros residenciales de acción educativa de Cataluña. Bordon, 60(3), 49-66.

Geenen, S., \& Powers, L. E. (2007). "Tomorrow is another problem": The experiences of youth in foster care during their transition into adulthood. Children and Youth Services Review, 29(8), 1085-1101.

Goldfarb, W. (1943). The effects of early institutional care on adolescent personality. Journal of Experimental Education, 12, 106-129.

Goldfarb, W. (1944). Infant rearing as a factor in foster home replacement. American Journal of Orthopsychiatry, 14, 162-166.

Goldfarb, W. (1945). Psychological privation in infancy and subsequent adjustment. American Journal of Orthopsychiatry, 14, 247-255. 
Goldfarb, W. (1947). Variations in adolescent adjustment of institutionally-reared children. American journal of Orthopsychiatry, 17, 449-457.

Goldfarb, W. (1955). Emotional and intellectual consequences of psychologic deprivation in infancy. A reevaluation. In P. Hoch \& J. Zubin (eds.), Psychopathology of Childhood. Nueva York: Grune \& Stratton, 105-119.

Hawkins-Rodgers, Y. (2007). Adolescents adjusting to a group home environment: A residential care model of re-organizing attachment behavior and building resiliency. Children and Youth Services Review, 29(9), 1131-1141.

Jones, L., \& Lansdverk, J. (2006). Residential education: Examining a new approach for improving outcomes for foster youth. Children and Youth Services Review, 28(10), 1152-1168.

Kahan, B. (1984). The state of the art. In: T. Philpot (ed.), Group care practice: The challenge of the next decade. Surrey: Business Press International Limited, 5-9.

Kliever, W. (1991). Coping in middle childhood: Relations to competence, type A behavior, monitoring, blunting, and locus of control. Developmental Psychology, 27, 689-697.

Legault, L., Anawati, M., \& Flynn, R. (2006). Factors favoring psychological resilience among fostered young people. Children and Youth Services Review, 28(9), 1024-1038.

Maclean, K. (2003). The impact of institutionalization on child development. Development \& Psychopathology, 15, 853-884.

Marinkovic, J. A., \& Backovic, D. (2007). Relationship between type of placement and competencies and problem behavior of adolescents in long-term foster care. Children and Youth Services Review, 29(2), 216-225.

McCoy, H., McMillen, J. C., \& Spitznagel, E. L. (2008). Older youth leaving the foster care system: Who, what, when, where, and why? Children and Youth Services Review, 30(7), 735-745.

Melton, G., Lyons P. \& Spaulding, W. (1998). No place to go: The civil commitment of minors. Nebraska: Lincoln, University of Nebraska Press.

Merino, R. \& Garcia, M. (2007). Itineraris de formació I inserció laboral dels joves a Catalunya. Informes breus, 4, Educació. Barcelona: Fundació Jaume Bofill.

Moran, P.B.; Vuchinicha, S. \& Hallb, N.K. (2004): Associations between types of maltreatment and substance use during adolescence. Child Abuse \& Neglect, 28(5), 565-574.

Rodgers, C.S., Lang, A.J., Laffaye, Ch., Satz, L.E., Dresselhaus, T.R. \& Stein, M.B. (2004). The impact of individual forms of childhood maltreatment on health behavior. Child Abuse \& Neglect, 28(5), 575586.

Romito, P.; Crismab, M. \& Saurel-Cubizollesc, M.J. (2003). Adult outcomes in women who experienced parental violence during childhood. Child Abuse \& Neglect, 27(10), 1127-1144.

Rutter, M. (1972). Maternal deprivation reassessed. Harmondsworth, Middlesex: Penguin Books.

Spitz, R. (1945a). Hospitalism: An inquiry into the genesis of psychiatric conditions in early childhood. Psychoanalytic Study of the Child, 1, 53-74.

Spitz, R. (1945b). Hospitalism: A follow-up report. Psychoanalytic Study of the Child, 1, 53-74.

Swanston, H.Y., Plunkett, A.M., O’Toole, B.I., Shrimpton, S.; Parkinson, P.N. \& Oates, R.K. (2003). Nine years after child sexual abuse. Child Abuse \& Neglect, 27(8), 967-984.

Weyts, A. (2004). The educational achievements of looked after children: Do welfare systems make a difference to outcomes? Adoption \& Fostering, 28(3), 7-19.

Whittaker, J.K. (1979). Caring for troubled children. San Francisco: Jossey-Bass. 